\title{
Computer based quantitative analysis of capillary abnormalities in systemic sclerosis and its relation to plasma concentration of von Willebrand factor
}

Agneta Scheja, Anita Åkesson, Izabella Niewierowicz, Lena Wallin, Marie Wildt, Frank A Wollheim

\begin{abstract}
Objectives-To evaluate an objective and quantitative method for assessment of capillary abnormalities in systemic sclerosis (SSc).

Methods-Nailfold capillaries were investigated by capillary microscopy and photographed in 17 consecutive SSc patients (five with diffuse cutaneous systemic sclerosis (dSSc) and 12 with limited cutaneous systemic sclerosis (1SSc)) and in 17 healthy controls. Investigators having no access to clinical data made drawings from magnified projections of coded photographs and analysed them using a computer program. Capillary density (capillary loops/mm in the distal row) and median capillary loop area were calculated. Presence of functional or organic arterial changes was evaluated by measurement of finger pressure with finger cooling. Plasma concentration of von Willebrand factor (VWF) was analysed using an enzyme linked immunosorbent assay (ELISA).
\end{abstract}

Results-In 16 of 17 SSc patients and 13 of 17 controls the technical quality of the photographs was sufficient for computer analysis. Capillary density was decreased in dSSc (median 6.9 loops $/ \mathrm{mm}$ ) and in ISSc (median 3.8 loops $/ \mathbf{m m}$ ) compared with healthy controls (8.9 loops $/ \mathrm{mm})$ and median capillary loop area was increased in dSSc $\left(7.3 \times 10^{-3} \mathrm{~mm}^{2}\right)$ and in 1SSc $\left(8.5 \times 10^{-3} \mathrm{~mm}^{2}\right)$ compared with healthy controls $\left(5.0 \times 10^{-3} \mathrm{~mm}^{2}\right)$. An inverse relation was found between capillary density and median capillary loop area in SSc patients. Plasma VWF was increased in patients (median $401 \mathrm{IE} / \mathrm{l}$ in dSSc and 409 IE/ $/$ in 1SSc) compared with controls matched for age and sex (median 276 IE/1). Computer based analysis showed capillary density below the control range and median capillary loop area above the control range in 14 of 16 SSc patients. Measurement of finger pressure with finger cooling showed organic vascular changes in nine of 13 SSc patients.

Conclusion-Computer based quantitative analysis has low interobserver variability and is a quantitative and sensitive method of assessing capillary abnormalities in SSc.

(Ann Rheum Dis 1996; 55: 52-56)
A microvascular abnormality is one of the characteristics of systemic sclerosis (SSc) and an immunologically mediated vascular injury is believed to play an important pathogenic part. ${ }^{1}$ The vascular disease in SSc manifests itself as Raynaud's phenomenon, an early symptom of the disease that may precede other symptoms by several years, notably in the limited form of the disease. ${ }^{2}$ Later, the vascular disease may contribute to serious and often irreversible organ manifestations such as irreversible digital ischaemia, cardiac involvement, renal failure, and pulmonary hypertension. Early in the disease, the vascular abnormality in SSc may be studied by capillary microscopy, in which characteristic capillary abnormalities as described by Maricq et al may be seen. ${ }^{3}$ Capillary microscopy in SSc is reported to have both diagnostic ${ }^{4}{ }^{5}$ and prognostic value. ${ }^{6}{ }^{7}$ Conflicting results have been presented regarding the relation of capillary changes to the degree of internal organ manifestations ${ }^{6-10}$ and to disease duration. ${ }^{611}$ Most reports of capillary microscopy in SSc have been qualitative, but semiquantitative ${ }^{11}$ and more time consuming quantitative methods based mainly on manual counting of capillaries have also been described..$^{10} 12$

Another method of studying vascular abnormalities is by measurement of finger systolic pressure before and after cold provocation, which permits evaluation of both occurrence of cold induced vasospasm and presence of organic arterial changes. ${ }^{13}$ Von Willebrand factor (VWF), a substance released mainly from injured endothelial cells, ${ }^{14}$ has been reported to be a marker of vascular disease and increased plasma concentrations have been found in SSc. ${ }^{15}$ We have previously reported that plasma concentrations of VWF correlate with serious vascular disease in SSc as measured by decreased glomerular filtration rate and increased pulmonary pressure. ${ }^{16}$

The purpose of the present study was to develop a quantitative and reproducible method for assessment of capillary abnormalities in SSc and to compare it with other methods used to determine vascular disease.

\section{Patients and methods}

Twenty three consecutive patients (six men and 17 women, aged $16-67$ years) admitted to the Department during an 18 month period with a suspected diagnosis of SSc were investigated using capillary microscopy. Seventeen had systemic sclerosis according to 
the American Rheumatism Association (ARA) criteria. ${ }^{17}$ Twelve had limited cutaneous SSc (ISSc) with skin changes restricted to the extremities and face, ${ }^{2}$ and five had diffuse cutaneous SSc (dSSc) with skin involvement of the trunk also. Six patients had suspected SSc with Raynaud's phenomenon and sclerodactyly, but did not fulfil the ARA criteria. Five patients were smokers.

Seventeen healthy volunteers (six men and 11 women, aged 25-62 years) served as controls in the study of capillary microscopy and 23 healthy persons (six men and 17 women, aged 15-68 years) matched for age and gender were controls in the analysis of VWF; three were smokers.

The nailfold capillaries of digit four bilaterally were examined by a stereozoom microscope (Olympus SZ-Pt) in $20 \times$ magnification. Immersion oil was applied to increase transparency of the skin. Temperature was controlled by ensuring that every subject was inside the building for a minimum of 15 minutes before the nailfold was examined. Photographs (figs 1A, 2A) of the centre of the nailfold were taken with a Kodak EPY-64T film and projected on a tracing paper. Computer analysis directly from the photographs was not possible because of insufficient contrast of the photographs; drawings were therefore performed by hand from magnified projections of technically satisfactory and coded photographs (figs 1B, 2B) and analysed in an area of $3 \times 3 \mathrm{~mm}$ centred with respect to the midpoint of the drawing. In many drawings all capillaries were included in the measure window, but in others a few capillaries were outside the measure window. The computer scanned the number of capillaries in the distal row and the area of the individual capillary loops which had been cut off at a standardised distance from the loop apexes $(1 \mathrm{~cm}$ on the drawing $=0.12 \mathrm{~mm}$ in reality). The image

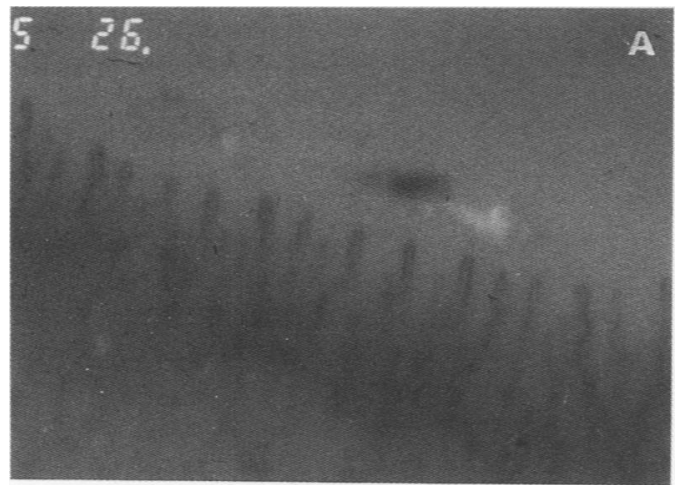

B

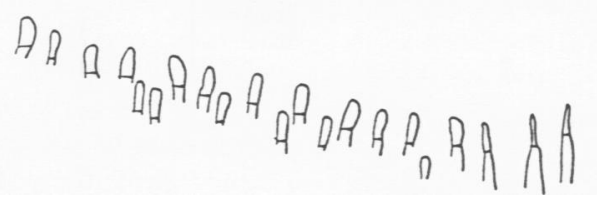

Figure 1 A: Photograph from capillary microscopy; $B$ : corresponding drawing. Healthy control.

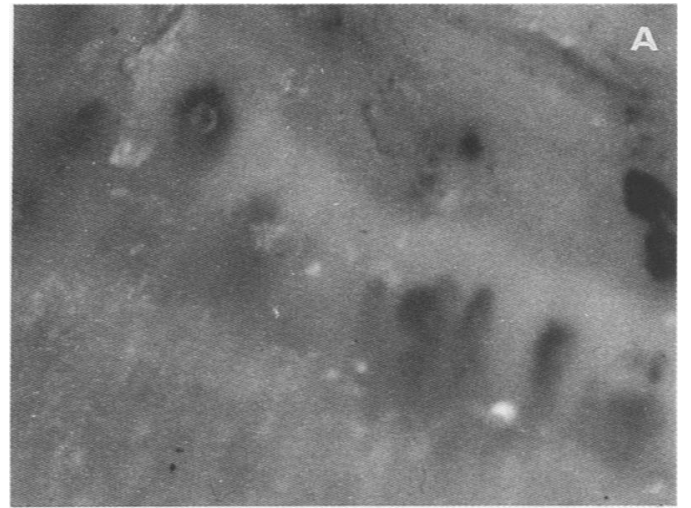

B

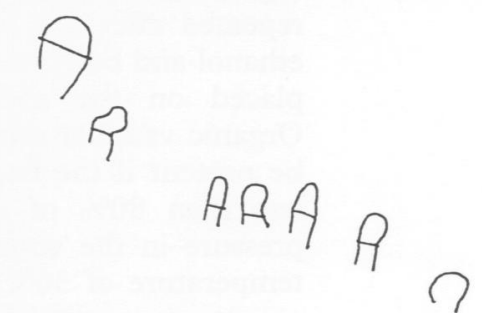

Figure 2 A: Photograph from capillary microscopy; $B$ : corresponding drawing. 42 year old man with dSSc of duration one year.

analysing system used was Leitz Quantimet 570 C. Calculations of capillary density (loops $/ \mathrm{mm}$ ) and median capillary loop area were based on all capillaries in the measure window. For calculation of the capillary density, at least six consecutive capillaries were required, and for calculation of median capillary loop area, at least four capillaries were measured. The total effective time consumed for each analysis was about 30 minutes, including photography, drawing, computer analysis, and calculation. The mean of left and right digit four is presented for patients. In the controls only the right digit four was investigated, as preliminary work has shown that no considerable difference between left and right fingers was present in controls. To test the reproducibility of the method 22 photos (eight in controls and 14 in patients) were assessed by two different investigators who performed independent drawings that were analysed by the computer. During the last 12 months of the study, capillary microscopy was performed according to a standardised schedule, by one of two rheumatologists with special interest in scleroderma (AS/A $\AA$ ). The capillary pattern was judged abnormal if there were definitely enlarged capillaries, avascular zones, or bleeding on more than two fingers.

A subgroup of patients were investigated by measurement of finger pressure with finger cooling for occurrence of cold induced vasospasm and presence of organic arterial changes. ${ }^{13}$ The measurement was performed at a room temperature of $18-19^{\circ} \mathrm{C}$ after 20 minutes of equilibration. Patients were dressed in normal indoor clothes and were not allowed to smoke for four hours before the investigation. The fingertip temperature of all fingers, the arm blood pressure and the finger systolic 
Table 1 Capillary density and median capillary loop area in 19 SSc patients and in 13 controls, and plasma concentration of von Willebrand factor (VWF) in 19 patients and 19 controls matched for age and gender

\begin{tabular}{|c|c|c|c|c|}
\hline & $\begin{array}{l}d S S c \\
(n=5)\end{array}$ & $\begin{array}{l}I S S c \\
(n=11)\end{array}$ & $\begin{array}{l}? S S c \\
(n=3)\end{array}$ & $\begin{array}{l}\text { Controls } \\
(n=13 \text { or }+19)\end{array}$ \\
\hline $\begin{array}{l}\text { Duration (years) } \\
\text { Capillary density (loops } / \mathrm{mm} \text { ) } \\
\text { Median capillary loop area }\left(10^{-3} \mathrm{~mm}^{2}\right) \\
\text { Plasma VWF (IE } / \text { ) }\end{array}$ & $\begin{aligned} 2(1-6) \\
6 \cdot 9(4 \cdot 4-8 \cdot 7)^{\star \star} \\
7 \cdot 3(5 \cdot 0-11 \cdot 3)^{\star \star} \\
401(135-1869) \mathrm{ns}\end{aligned}$ & $\begin{array}{c}2(1-12) \\
3 \cdot 8(2 \cdot 6-11 \cdot 2)^{\star \star \star} \\
8 \cdot 5(3 \cdot 5-15 \cdot 0)^{\star \star} \\
409(233-1150)^{\star \star}\end{array}$ & $\begin{array}{r}-6 \cdot 7(6 \cdot 1-7 \cdot 7)^{\star} \\
7 \cdot 8(7 \cdot 0-9 \cdot 0)^{\star \star} \\
525(235-550) \mathrm{ns}\end{array}$ & $\begin{array}{r}- \\
8 \cdot 9(7 \cdot 5-11 \cdot 2) \\
5 \cdot 0(4 \cdot 0-6 \cdot 0) \\
+276(111-710)\end{array}$ \\
\hline
\end{tabular}

Values are median (range).

$\dagger 19$ controls matched for age and gender. dSSc = Diffuse cutaneous SSc; $1 S S c=$ limited cutaneous SSc; ?SSc $=$ suspected SSc. Significance of difference between patients and controls: ${ }^{\star} p<0.05 ;{ }^{\star \star} p<0.01 ;{ }^{\star \star \star} p<0.001$.

pressure of the mid phalanx of the two most severely symptomatic fingers were measured before and after local cooling with water at $10^{\circ} \mathrm{C}$, perfused through a specially constructed digital blood pressure cuff. The procedure was repeated after oral intake of $30 \mathrm{ml}$ of $40 \%$ ethanol and body warming with a heating pad placed on the abdomen for 15 minutes. Organic vascular changes were considered to be present if the finger systolic pressure was less than $80 \%$ of simultaneous arm blood pressure in the contralateral arm at a finger temperature of $30^{\circ} \mathrm{C}$ or more. Cold induced vasospasm was considered to be present when finger systolic pressure was less than $65 \%$ of simultaneous arm blood pressure at a finger temperature of $10^{\circ} \mathrm{C}$.

Plasma concentration of VWF was analysed with an enzyme linked immunosorbent assay (ELISA). Haemate (Hoechst), a commercially available VWF concentrate with a composition of multimers similar to that in vivo, was used as a standard. Blood samples were drawn from patients between 09:00 and 10:00 after 30 minutes of rest in bed with no smoking. Measurement of finger pressure was performed in the afternoon. The controls were not allowed to practise any form of exercise or to smoke for at least 15 minutes before the blood sample was drawn.

\section{STATISTICS}

The statistical significance of the difference between two groups was calculated with the Mann-Whitney $U$ test and the relation between two variables was calculated with Spearman's $\rho$. The interobserver variation was calculated with analysis of variance.
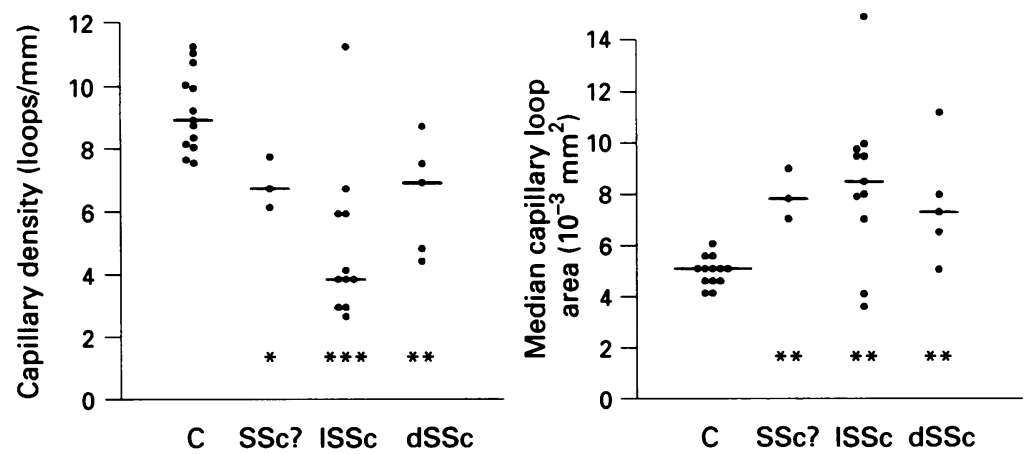

Figure 3 Capillary density (left) and median capillary loop area (right) in 19 SSc patients divided according to skin involvement (NSSc=limited $S S c$; dSSc = diffuse SSc), and in 13 healthy controls $(C)$. SSc? = Suspected SSc. Significant differences between patients and controls: ${ }^{*}<0.05 ;{ }^{\star *} p<0.01 ;{ }^{\star \star *} p<0.001$. Medians marked by horizontal bars.

\section{Results}

In 19 of 23 patients and in 13 of 17 controls, the photographs were of sufficiently good technical quality to allow accurate drawings to be made. Four patients were excluded because of technically unsatisfactory photographs: of these, three had suspected SSc and one had ISSc. Among the controls, the photographs from two men and two women were judged unsatisfactory. Table 1 shows capillary density and median capillary loop area in the five patients with dSSc and 11 with $1 S S c$, the three patients with suspected SSc and the 13 controls. Compared with the controls, the capillary density was decreased (fig 3A) and the median capillary loop area was increased (fig 3B) in patients with dSSc, 1SSc and suspected SSc. There was a tendency for lower capillary density in patients with ISSc than in dSSc $(p=0 \cdot 06)$. Only two patients with SSc (one ISSc and one dSSc) had computer results within the control range. None of these patients had Raynaud's phenomenon.

An inverse relation was found between capillary density and median capillary loop area $(p<0.01, \rho=-0.67)$ in SSc patients. The interobserver variation between two independent observers was $0 \cdot 25 \%$ for capillary density and 5\% for capillary loop area. A great overlap between patients and controls was found for plasma concentration of VWF (table 1, fig 4), but SSc patients had greater median plasma concentration $(p<0.02)$. No significant correlation was found between plasma VWF and capillary density $(p=0 \cdot 28)$

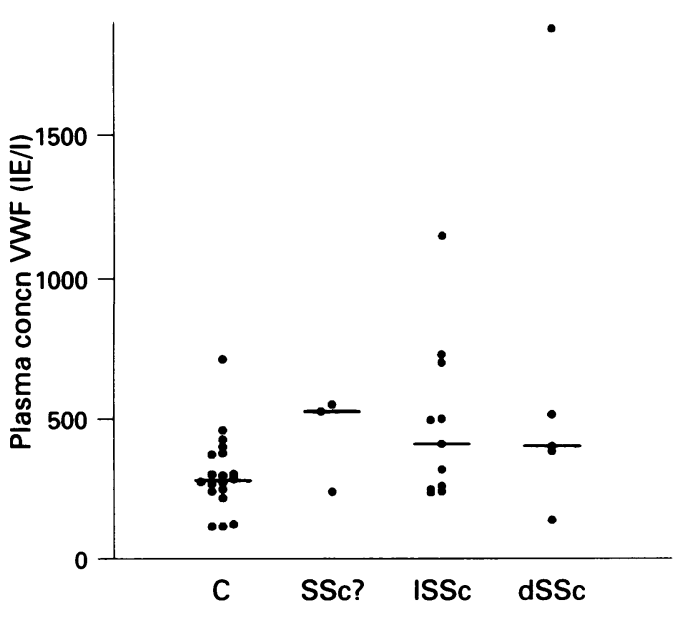

Figure 4 Plasma concentration of von Willebrand factor (VWF) in 19 SSc patients, divided according to skin involvement ( $S S S c=$ limited $S S c ; d S S c=$ diffuse $S S c$ ), and in 19 healthy controls matched for age and gender. SSc? = Suspected SSc. Medians are marked by horizontal $S S c$ ?
bars. 
Table 2 Finger pressure with finger cooling in the two most severely affected fingers in 16 SSc patients

\begin{tabular}{|c|c|c|c|c|c|c|c|}
\hline & $A P 30^{\circ} \mathrm{C}(\%)$ & No. fingers & Mean (\%) & & $10^{\circ} \mathrm{C} / 30^{\circ} \mathrm{C}(\%)$ & No. fingers & Mean (\%) \\
\hline \multicolumn{4}{|c|}{ Organic vascular changes } & \multicolumn{4}{|c|}{ Cold induced vasospasm } \\
\hline None & $>80$ & 13 & 92 & None & $>65$ & 10 & 88 \\
\hline Grade 1 & $<80 \geqslant 70$ & 5 & 75 & Grade 1 & $>50 \leqslant 65$ & 6 & 60 \\
\hline Grade 2 & $<70 \geqslant 50$ & 5 & 63 & Grade 2 & $>25 \leqslant 50$ & 4 & 43 \\
\hline Grade 3 & $<50$ & 9 & 35 & Grade 3 & $\leqslant 25$ & 12 & 3 \\
\hline
\end{tabular}

AP $30^{\circ} \mathrm{C}=$ Finger pressure/arm pressure at a finger temperature of $30^{\circ} \mathrm{C} ; 10^{\circ} \mathrm{C} / 30^{\circ} \mathrm{C}=$ finger pressure at $10^{\circ} \mathrm{C} /$ finger pressure at $30^{\circ} \mathrm{C}$.

or between plasma VWF and median capillary loop area $(\mathrm{p}=0 \cdot 12)$.

Sixteen patients (13 SSc and three suspected SSc) were also investigated with measurement of finger pressure with finger cooling. Three patients were not investigated because their diagnosis was established at the admitting hospital; all three had pronounced capillary abnormalities. In 11 patients with computer results outwith the control range, finger pressure indicated organic arterial changes, and in one patient both methods gave normal results. However, in four patients there was a discrepancy between the results obtained by the different methods, those from computer analysis being outwith the control range, while finger pressure indicated no arterial abnormality apart from cold induced vasospasm. Table 2 shows the results for finger pressure with finger cooling; the degree of vasospasm is expressed as finger pressure at $10^{\circ} \mathrm{C} /$ finger pressure at $30^{\circ} \mathrm{C}$. The seven patients who were not investigated with finger pressure with finger cooling were three SSc with computer analysis far outwith the control range and one SSc and three suspected SSc unevaluable in the computer analysis.

In 11 patients (eight SSc and three suspected SSc) the computer analysis was also compared with results from standardised capillary microscopy. Both methods indicated abnormal capillaries in five patients, and normal capillaries in one patient. In three patients, marked abnormalities in the quantitative analyses were obtained while the routine examination was judged as normal. Two patients had borderline results in the computer analysis and normal routine examination.

\section{Discussion}

Plasma concentrations of von Willebrand factor, a biochemical marker of vascular disease, show a large degree of overlap between patients with serious and less serious disease $\mathrm{e}^{16}$ and between patients and controls as found in the present study. This is complicated further because standardisation of the collection of blood samples is difficult, as even minor differences in body activity or position may influence plasma concentrations. ${ }^{18-20}$

Capillary microscopy is an attractive and simple method for the study of capillary abnormalities, but there is a need for both a quantitative and a qualitative assessment. We tried without success to analyse the photographs directly by computer: the contrast of the picture was not good enough. It did, however, prove possible to draw outlines of the capillary bed on tracing paper before performing the computer analysis. The reproducibility obtained between two investigators was satisfactory with respect to capillary density, but less sufficient for median capillary loop area; determination of capillary loop area using this equipment cannot be recommended. We investigated the fourth finger because of our own unpublished observations, confirmed by Houtman et $a l^{5}$ who described producing the fewest nonevaluable photographs and the best discriminatory capacity of the method when using this finger. The technical quality of the photographs was judged satisfactory to allow drawings to be made in $83 \%$ of the patients and $76 \%$ of the controls, which are slightly greater percentages than presented by others. ${ }^{521}$ More stringent criteria regarding technical quality and rejected photographs would probably further increase the reproducibility, but a greater percentage of patients would escape evaluation by this method. In the present study, a minimum of six capillaries was required for calculations of capillary density, and four for calculations of median capillary loop area. If the number had been increased, the reproducibility would have improved but, again, more patients would have escaped evaluation, in particular those patients with serious vascular disease and low capillary density. Furthermore, a larger window would have given problems with the sharpness of the picture, as a result of the curvature of the finger. Three of four patients unevaluable because of unsatisfactory photographs had suspected SSc, giving a high percentage of rejected photographs in suspected SSc $(50 \%)$. This might indicate difficulties with capillary microscopy in the early oedematous stage of the disease, because of limited transparency of the skin. However, it is possible that more advanced equipment might increase the percentage of evaluable photographs in this subgroup.

The sensitivity of the computer analysis was nevertheless reasonably good: 14 of $16(88 \%)$ evaluable patients with SSc showed computer results outwith the control range, in addition to all three patients with suspected SSc. The two patients with SSc according to the ARA criteria and a computer analysis within the control range had no Raynaud's phenomenon, suggesting that their capillaries were functionally normal. The computer analysis was more sensitive than finger pressure with finger cooling in the detection of organ vascular changes. This finding is in agreement with Lee et $a l^{22}$ who compared capillary microscopy to the measurement of capillary blood flow. The 
tendency for lower capillary density in 1SSc compared with dSSc is of interest, as pulmonary hypertension is reported to be more frequent in 1SSc than in dSSc, ${ }^{23}$ and in a case control postmortem study ${ }^{24}$ more pronounced pulmonary vascular changes were found in ISSc than in dSSc. However, this finding requires confirmation in a larger patient population.

The low degree of overlap between patients and controls is in good accordance with the findings of Carpentier et $a l^{25}$ who showed the excellent discriminatory capacity of capillary microscopy. Lefford et $a l^{10}$ found abnormal indices of capillary microscopy in only six of nine patients with SSc, which might be explained by the different techniques used or by differences in the patient populations studied. The percentage of patients lacking Raynaud's phenomenon may influence the degree of overlap.

We conclude that the method we have presented gives a quantitative measure of capillary density with low interobserver variability. The predictive value of the method is being studied in a prospective study in new consecutive SSc patients. With an improved photographic technique making possible computer analysis directly from the photograph, or a micrometer mounted in the ocular lens of the microscope allowing direct counting of capillaries $/ \mathrm{mm}$, the method may become a useful tool in clinical routine assessment of patients with Raynaud's phenomenon.

The authors thank photographer Ragnar Mårtensson, Department of Dermatology, Lund University Hospital, for development of the computer program.

This study was supported by grants from the Österlund Foundation, the Kock Foundation, Riksforbundet mot Reumatism, and the Medical Faculty of the University of Lund.

1 Kahaleh B. Vascular disease in scleroderma. Endothelial T lymphocyte-fibroblast interactions. Rheum Dis Clin N Am 1990; 16: 53-73.

2 LeRoy C, Black C, Fleischmajer R, et al. Scleroderma (systemic sclerosis): Classification, subsets and pathogenesis. F Rheumatol 1988; 15: 202-5.

3 Maricq H, LeRoy C. Patterns of finger capillary abnormalities in connective tissue disease by 'Wide-field' microscopy. Arthritis Rheum 1973; 16: 619-28.

4 Maricq H R, LeRoy E C, d'Angelo W A, et al. Diagnostic potential of in vivo capillary microscopy in scleroderma and related disorders. Arthritis Rheum 1980; 23: 183-9.
5 Houtman P, Kallenberg C, Fidler V, Wouda A. Diagnostic significance of nailfold capillary patterns in patients with

6 Maricq H, Spencer-Green G, LeRoy C. Skin capillary Maricq H, Spencer-Green G, LeRoy C. Skin capillary
abnormalities as indicators of organ involvement in abnormalities as indicators of organ involvement in
scleroderma (systemic sclerosis), Raynaud's syndrome scleroderma (systemic sclerosis), Raynaud's synd
and dermatomyositis. Am $\mathcal{F}$ Med 1976; 61: 862-70.

7 Zufferey $P$, Depairon M, Chamot A-M, Monti M. Prognostic significance of nailfold capillary microscopy in patients with Raynaud's phenomenon and sclerodermapattern abnormalities. A six-year follow-up study. Clin Rheumatol 1992; 11: 536-41.

8 Lovy M, MacCarter D, Steigerwald J. Relationship between nailfold capillary abnormalities and organ involvement in systemic sclerosis. Arthritis Rheum 1985; 28: 496-501.

9 Statham B N, Rowell N R. Quantification of the nail fold capillary abnormalities in systemic sclerosis and Raynaud's syndrome. Acta Derm Venereol (Stockh) 1986; 66: 139-43.

10 Lefford F, Edwards J C W. Nailfold capillary microscopy in connective tissue disease: a quantitative morphological analysis. Ann Rheum Dis 1986; 45: 741-9.

11 Lee P, Leung F, Alderdice C, Armstrong S. Nailfold capillary microscopy in the connective tissue diseases: A semiquantitative assessment. $\mathcal{F}$ Rheumatol 1983; 10: 930-8.

12 Maricq $\mathrm{H}$. Comparison of quantitative and semiquantitative estimates of nailfold capillary abnormalities in scleroderma spectrum disorders. Microvasc Res 1986; 32: 271-6.

13 Arneklo-Nobin B, Johansen K, Sjöberg T. The objective diagnosis of vibration-induced vascular injury. Scand $\mathcal{F}$ Work Environ Health 1987; 13: 337-42.

14 Brinkhous K M, Sultzer D L, Reddick R L, Griggs T R. Elevated plasma von Willebrand factor ( $v$ Wf $)$ levels as an index of acute endothelial injury: use of a hypotonic injury model in rats. Fed Proc 1980; 39: 630.

15 Kahaleh B, Osborn I, LeRoy C. Increased factor VIII/ von Willebrand factor antigen and von Willebrand factor activity in scleroderma and in Raynaud's phenomenon. Ann Int Med 1981; 94: 482-4.

16 Scheja A, Eskilsson J, Ákesson A, Wollheim F A. Inverse relation between plasma concentration of von Willebrand
factor and CrEDTA clearance in systemic sclerosis. factor and CrEDTA clearance

17 Masi A, Rodnan G, Medsger T Jr, et al. Preliminary criteria for the classification of systemic sclerosis (scleroderma). Arthritis Rheum 1980; 23: 581-90.

18 Farrell A, Williams R, Stevens C, Lawrie A, Cox N, Blake D. Exercise induced release of von Willebrand factor: evidence for hypoxic reperfusion microvascular injury in rheumatoid arthritis. Ann Rheum Dis 1992; 51: $1117-22$.

19 Blann A. Von Willebrand factor, exercise, and ischaemia/ reperfusion injury. Ann Rheum Dis 1993; 52: 245.

20 Blann A, Jayson M I V, Pope M H, Kaigle A M, Wilder D, Weinstein J N. Postural variation in von Willebrand factor antigen. Ann Rheum Dis 1993; 52: 82.

21 Day R O, Wacher T, Cairns D, Conners G, McGrath M. Nailfold capillary circulation in osteoarthritis. $B r \dot{f}$ Rheumatol 1993; 32: 1062-5.

22 Lee P, Sarkozi J, Bookman A, Keystone E, Armstrong S. Digital blood flow and nailfold capillary microscopy in Raynaud's phenomenon. $\mathcal{F}$ Rheumatol 1986; 13: 564-9.

23 Ungerer $R$, Tashkin D, Furst D, et al. Prevalence and clinical correlates of pulmonary arterial hypertension in progressive systemic sclerosis. $\mathrm{Am} f \mathrm{Med} 1983$; 75: 65-74.

$24 \mathrm{Al}$-Sabbagh $\mathrm{R}$, Steen V, Zee B, et al. Pulmonary arterial histology and morphometry in systemic sclerosis: a casecontrol autopsy study. $\mathcal{F}$ Rheumatol 1989; 16: 1038-42.

25 Carpentier P, Maricq H. Microvasculature in systemic sclerosis. Rheum Dis Clin N Am 1990; 16: 75-91. 